\title{
Type C Personality and Depression Among Newly Diagnosed Breast Cancer Patients: The Mediating Role of Sense of Coherence
}

This article was published in the following Dove Press journal: Neuropsychiatric Disease and Treatment

\author{
Miao Wei, ' Lina Guo, (D) \\ Yiru Zhu,' Yvru Guo, ${ }^{2}$ \\ Suyuan Yv,' \\ Genoosha Namassevayam, (iD) \\ Wenhua Xue, ${ }^{3}$ Jieyao Li, ${ }^{4}$ \\ Lifeng Li, ${ }^{4}$ Zhibo Shen, ${ }^{4}$ \\ Junlin Yv, ${ }^{4}$ Zijia Zhu, ${ }^{3}$ \\ Wenbin Wang, ${ }^{3}$ Yanjin Liu, \\ Jie Zhao, ${ }^{3} \mathrm{Fu} \mathrm{Chen}^{6}$ \\ 'Department of Neurology, The First \\ Affiliated Hospital of Zhengzhou University, \\ Zhengzhou, Henan Province, People's \\ Republic of China; ${ }^{2}$ Department of \\ Orthopedics, The First Affiliated Hospital of \\ Zhengzhou University, Zhengzhou, Henan \\ Province, People's Republic of China; \\ ${ }^{3}$ Department of Pharmacy, The First \\ Affiliated Hospital of Zhengzhou University, \\ Zhengzhou, Henan Province, People's \\ Republic of China; ${ }^{4}$ Department of \\ Oncology, The First Affiliated Hospital of \\ Zhengzhou University, Zhengzhou, Henan \\ Province, People's Republic of China; \\ ${ }^{5}$ Department of Nursing, The First Affiliated \\ Hospital of Zhengzhou University, \\ Zhengzhou, Henan Province, People's \\ Republic of China; ${ }^{6}$ Department of Medical \\ Administration, The First Affiliated Hospital \\ of Zhengzhou University, Zhengzhou, \\ Henan Province, People's Republic of China
}

Correspondence: Yanjin Liu

Department of Nursing, The First Affiliated Hospital of Zhengzhou University, PO Box 450052, Zhengzhou, Henan Province, People's Republic of China Email liu-yanjin@I26.com

Jie Zhao

Department of Pharmacy, The First Affiliated Hospital of Zhengzhou University, PO Box 450052, Zhengzhou, Henan Province, People's Republic of China Email zhaojie2016@I26.com
Purpose: This study aims to explore the mediating role of sense of coherence in the relationship of type $\mathrm{C}$ personality and depression among newly diagnosed breast cancer patients.

Methods: A descriptive and correlational survey was conducted in 600 breast cancer patients aged $\geq 18$ years from September 2018 to March 2019 in Zhengzhou, China. The demographic questionnaire, Cancer Behavior Scale, Sense of Coherence Scale and Hamilton Depression Scale were included in this study. Data analysis was performed by correlation analysis, multiple linear regression analysis, and structural equation modeling.

Results: The valid questionnaires were 575 (effective response rate: 95.8\%). The score of sense of coherence was negatively correlated with type $\mathrm{C}$ personality and depression $(r=$ $-0.41, P<0.01 ; r=-0.58, P<0.01)$; the score of type $\mathrm{C}$ personality and depression were positively correlated $(r=0.51, P<0.01)$. The results of multiple linear regression analysis revealed that the effect of type $C$ personality on depression was partly mediated by sense of coherence, which was confirmed by structural equation modeling. The mediation effect accounts for $45.2 \%(0.269 / 0.594)$ of the total effect.

Conclusion: The results of this study revealed that sense of coherence as a partial mediating role is essential for reducing the influence of type $\mathrm{C}$ personality on depression. Early and targeted psychological interventions on sense of coherence are needed to alleviate the symptom of depression in newly diagnosed breast cancer patients.

Keywords: breast cancer, sense of coherence, type C personality, depression, mediation effect

\section{Introduction}

Breast cancer is one of the commonest malignant tumors in the world and a leading cause of death for women. The International Agency for Research on Cancer ${ }^{1}$ estimates that there are about 18.1 million newly diagnosed cancer patients worldwide in 2018 , of which 2.1 million are breast cancer. Compared with other countries, the incidence of breast cancer in China is lower. ${ }^{2}$ However, since the 1990 s, breast cancer incidence has grown at more than twice the rate of global incidence. ${ }^{3}$ Breast cancer has become the sixth leading cause of death in Chinese women. Patients diagnosed with breast cancer are often exposed to negative emotions, such as anxiety, depression and some other psychological consequences. ${ }^{4,5}$ Breast cancer patients are more likely to be depressed than the general population, ${ }^{6,7}$ which is related to the particularity of the diagnosis, treatment and rehabilitation process of the disease and the change of the body image. In addition, the psychosocial problems of breast cancer patients have not been released or 
treated for a long time, which may seriously affect the quality of life of breast cancer patients. ${ }^{8,9}$ Perhaps, as a result, the treatment and intervention of depression in newly diagnosed breast cancer patients has drawn an extensive attention. Comprehensive knowledge of the determinants of depression in breast cancer patients is the fundamental first step to ameliorate their symptoms.

Previous studies have shown that type $\mathrm{C}$ personality was a predictive variable of breast cancer. ${ }^{10}$ In 1988 , Baltrusch, ${ }^{11}$ the first one who proposed type $\mathrm{C}$ pattern (cancer character or type $\mathrm{C}$ personality), believed that it is closely related to the occurrence of malignant tumors through a psychological-physiological mechanism. ${ }^{12}$ As the long-term negative emotions of the type $\mathrm{C}$ personality group cannot be vented, coupled with negative life events, bad behavior, vitamin deficiency and so on, are thought to cause neuroendocrine and immune system disorders, which may lead to tumors. ${ }^{13}$ In addition, compared with other cancers, breast cancer patients are more likely to exhibit type $\mathrm{C}$ personality, which was related to selfimage disorder and impaired self-esteem. ${ }^{10}$ Some researchers believe that type $\mathrm{C}$ personality can not only directly affect individual depressive symptoms, but also indirectly reduce the occurrence of depression through some positive psychological mechanisms. ${ }^{12}$ Therefore, an in-depth study of the relationship between type $\mathrm{C}$ personality and depression is essential to understand and to identify strategies to promote the mental health of newly diagnosed breast cancer patients.

In 1979, Antonovsky proposed the Salutogenic Model of Health, which considers that the protective factors that promote mental health can activate and enhance the available resources of individuals when facing stress, so that they can maintain mental health successfully. Sense of coherence (SOC) is a core concept of the Salutogenic Model of Health. It reflects an individual's general perception and feeling of the outside world, and it is an inherently stable and lasting self-confidence. ${ }^{14}$ The higher SOC, the stronger the individual's ability to use resources and cope with pressure. SOC consists of three components: comprehensibility (individual's logical understanding and cognitive ability of life), manageability (individual's ability to perceive and control life), and meaningfulness (individual's emotional input into life). ${ }^{15}$ Some studies ${ }^{16-18}$ have indicated that SOC not only was a protective factor against depression but also can be used as a positive resource for anti-depression. People with a higher level of SOC reported fewer mental symptoms, such as anxiety, depression and so on, with the prevalence of depression significantly reduced. ${ }^{19}$ As a predictive variable for health-related quality of life in breast cancer patients, SOC acts a primary effect compared with spirituality and religious coping. ${ }^{20,21}$ SOC has also been proposed as a mediator in the relationship of perceived stress and depression among older stroke patients. ${ }^{22}$ But, the potential influence of type $\mathrm{C}$ personality on depression and the association of SOC and depression among newly diagnosed breast cancer patients have not been explored. Furthermore, the mediation effect of the SOC in the relationship of type $\mathrm{C}$ personality and depression in newly diagnosed breast cancer patients have not been confirmed. Therefore, the objective of this present study is to explore the direct and indirect association between type $\mathrm{C}$ personality and depression and to validate the mediation mechanism of SOC on this relationship among newly diagnosed breast cancer patients.

Pondering the associations of the aforementioned variables, this study aims to use a mediation model to clarify the direct/indirect association and the underlying mechanisms of these variables. ${ }^{23}$ Therefore, the following hypotheses were proposed: hypothesis 1 (H1), type C personality and depression are positively and directly correlated; hypothesis $2(\mathrm{H} 2)$, type C personality and SOC are negatively and directly correlated; hypothesis 3 (H3), SOC and depression are negatively and directly correlated; and hypothesis 4 (H4), type $\mathrm{C}$ personality and depression are positively and indirectly correlated through SOC as a mediator. $^{24-26}$

\section{Methods}

\section{Design, Setting and Sample}

This descriptive and correlational survey was conducted in the department of breast surgery and oncology, First Affiliated Hospital of Zhengzhou University, Zhengzhou, China from September 2018 to March 2019 by using convenience sampling. Before starting the study, participants should be aware of the purpose of the study and provide informed consent. Participants were required to meet the following criteria. Inclusion criteria: (1) was newly diagnosed breast cancer at least one postoperative histological evaluation, ${ }^{27}$ (2) was able to communicate and cooperate with researchers through words or language, (3) $\geq 18$ years old, (4) knew the purpose of this study and volunteered to participate. Exclusion criteria: (1) with severe cognitive impairment, (2) with severe heart failure, respiratory failure and other serious acute or chronic 
diseases. According to the criterion proposed by Thompson $^{28}$ in 2000, the ratio of sample size and observed variables is at least 10:1 to $15: 1$. Thus, the needed number of participants was determined as 190 to 285 . However, 600 individuals were recruited to this survey in fact.

\section{Data Collection and Measurements}

Before data collection, researchers were obliged to explain to participants the purpose of the study and the points for attention in filling out the questionnaire. The investigators of data collection were professionally trained; the one-toone and face-to-face data collection method was employed. The questionnaires were completed by participants themselves within 1 week after the diagnosis, and immediately following completion.

The following questionnaires were used in this research: demographic characteristic questionnaire (ie, age, gender, body mass index (BMI), marital status, profession, degree of education, type of surgery, monthly income, dietary habit, and contact information); Cancer Behaviors Scale (CB); ${ }^{29}$ Sense of Coherence Scale (SOC); and Hamilton Depression Scale (HAMD).

\section{Cancer Behaviors Scale}

The Chinese version of CB was used to screen the cancer behaviors. This scale is currently the most commonly used tool for assessing type $\mathrm{C}$ personality. It includes 97 items, nine dimensions: Anxiety, Depression, Anger, Exin-anger, Exout-anger, Rational, Control, Optimism, and Social Support. $^{29}$ Each item is scored on a 4-point Likert scale ranging from 1 (rarely or not at all) to 4 (most or all the time), and some reverse scoring items range from 4 to 1 . The total score ranges from 97 to 388 points, where a higher score indicates a more obvious type $\mathrm{C}$ personality. In this study, the Cronbach's alpha reliability coefficient for the total $\mathrm{CB}$ was 0.800 .

\section{Sense of Coherence Scale}

This scale was developed by Antonovsky, ${ }^{30}$ consisted of three dimensions (comprehensibility, manageability, and meaningfulness) and 13 items, which has been found capable of evaluating the internal stability of individuals. The items on this scale are recorded on a 7-point Likert scale, and each item ranges from 1 to 7 . The total score of this scale ranges from 13 to 91 . The higher total score indicates stronger SOC. ${ }^{22}$ In our study, the Cronbach's alpha of SOC was 0.765 .

\section{Hamilton Depression Scale}

The HAMD scale, compiled by Hamilton in 1960, is the most widely used scale in the clinical assessment of depression. Its total score better reflects the severity of the disease. ${ }^{31}$ HAMD-24 was used in this study, with 24 items, seven dimensions. Most items range from 0 to 4 (none; mild; moderate; severe; very severe), and few items range from 0 to 2 (none; mild to moderate; severe). The total score ranges from 0 to 76, in which higher score denotes by the more serious depression. According to Davis JM's classification criteria, ${ }^{29}$ total score of $>20$ points can be considered to be depression. For our study, the Cronbach's alpha was 0.825 .

\section{Ethical Approval}

Prior to this research, the research protocols have been approved by the Ethics Committee of the first affiliated Hospital of Zhengzhou University in China. The objective of this study was communicated with all participants and the written informed consent was obtained. This study was conducted in accordance with the Declaration of Helsinki. Questionnaires were collected anonymously in order to protect the privacy of participants.

\section{Statistical Analysis}

The IBM SPSS Statistics 23.0 was used for statistical analyses, such as descriptive analysis, Pearson correlation analysis and multiple linear regression analysis. The structural equation modeling (SEM) was constructed by the AMOS Graphics 22.0 to analyze the effect of type $\mathrm{C}$ personality and SOC on depression. All statistical analyses were two-tailed text and were evaluated at a level of statistical significance of 0.05 . The sample characteristics were described by using percentages and frequencies. Descriptive statistics for type $\mathrm{C}$ personality, SOC, and depression scores were described by means, standard deviations and range of scores. Pearson correlation analysis was performed to explore the relationship among the type C personality, SOC, and depression. Multiple linear regression was established to explain whether SOC could mediate the relationship of type $\mathrm{C}$ personality and depression. Some epidemiological investigation reports in $\mathrm{China}^{32,33}$ and abroad $^{34,35}$ showed that age, marital status, type of surgery, degree of education and personal income are related to depression in breast cancer patients. Therefore, a triple multiple linear regression analysis was established in this study. Firstly, the above-mentioned five sociodemographic factors (ie, age, marital status, type of surgery, degree of education and monthly income) were adopted in Model I as controlled variables. Then, 
on the basis of Model I, type $\mathrm{C}$ personality dimensions were added in Model II. In addition, Model III was built with dimensions of SOC based on the Model II. Finally, the SEM and the bootstrap method (2000 replicates) ${ }^{36}$ were employed to validate the hypotheses of the relationship among type $\mathrm{C}$ personality, SOC and depression, by using the AMOS Graphics 22.0. The bootstrap method is more accurate than Baron and Kenny's ${ }^{23}$ or Sobel's ${ }^{37}$ methods and has higher statistical power. The structural model pathway is shown in Figure 1.

\section{Results}

\section{Sample Characteristics}

Excluded the questionnaire with a completion rate below $80 \%$ or low-quality writing. Finally, the total number of valid questionnaires was 575 (effective response rate: 95.8\%). The age of the breast cancer patients was ranged from 18 to 78 years old, and the mean age was $42.72(S D=11.99)$. The detailed demographic characteristics of the participants are provided in Table 1.

\section{Description of the Measurements}

The means, standard deviations of the CB, SOC, HAMD were $229.22(S D=23.93), 73.31(S D=8.97), 17.30(S D=$ 7.14). The score of the CB, SOC, HAMD were ranged from 171 to 296,38 to 87,0 to 40 , respectively. In addition, $27.0 \%$ $(\mathrm{N}=575)$ of participants had a HAMD score of more than 20 and were identified as suffering from depression.

\section{Correlation Analysis of $\mathrm{CB}, \mathrm{SOC}$ and HAMD}

The relationships among $\mathrm{CB}, \mathrm{SOC}$ and HAMD are performed in Table 2. It showed that $\mathrm{CB}$ was negatively correlated with SOC $(r=-0.40, P<0.01)$. The CB score
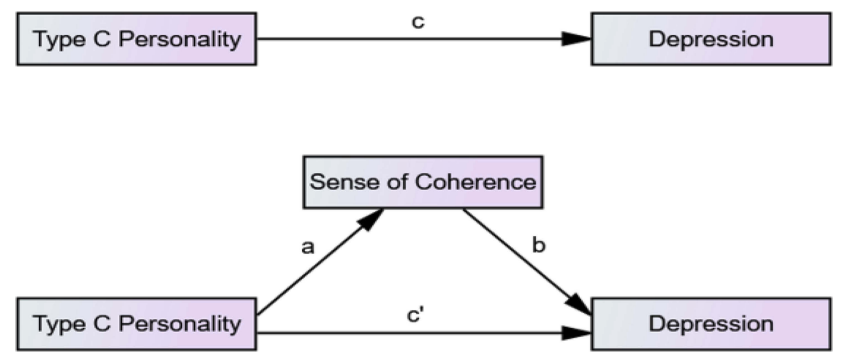

Figure I A structural model pathway for mediating the role of SOC in the relationship of type $C$ personality and depression. a: The relationship between type C personality and SOC; b: The relationship between SOC and depression; c: The relationship between type $C$ personality and depression; c': The relationship between type $C$ personality and depression after adopting SOC as a mediator.
Table I Demographic Characteristics of the Participants $(\mathrm{N}=$ 575)

\begin{tabular}{|c|c|c|c|}
\hline Factors & Group & $\mathbf{n}$ & $\%$ \\
\hline \multirow[t]{6}{*}{ Age } & $18-29$ & 84 & 14.6 \\
\hline & $30-39$ & 142 & 24.7 \\
\hline & $40-49$ & 195 & 33.9 \\
\hline & $50-59$ & 106 & 18.5 \\
\hline & $60-69$ & 34 & 5.9 \\
\hline & $70-78$ & 14 & 2.4 \\
\hline \multirow[t]{2}{*}{ Gender } & Male & 9 & 1.6 \\
\hline & Female & 566 & 98.4 \\
\hline \multirow[t]{2}{*}{ Spouse Status } & Have & 456 & 79.3 \\
\hline & No & 119 & 20.7 \\
\hline \multirow[t]{5}{*}{ Degree of Education } & Elementary school or below & 154 & 26.8 \\
\hline & Junior high school & 127 & 22.1 \\
\hline & High school & 122 & 21.2 \\
\hline & Undergraduate college & 167 & 29.0 \\
\hline & Postgraduate or above & 5 & 0.9 \\
\hline \multirow[t]{2}{*}{ Type of Surgery } & Mastectomy & 367 & 63.8 \\
\hline & Lumpectomy & 208 & 36.2 \\
\hline \multirow[t]{5}{*}{ Monthly Income (RMB) } & $<3000$ & 296 & 51.5 \\
\hline & $3,000-5,000$ & 145 & 25.2 \\
\hline & $5,000-10,000$ & 122 & 21.2 \\
\hline & $10,000-20,000$ & 9 & 1.6 \\
\hline & $>20,000$ & 3 & 0.5 \\
\hline \multirow[t]{7}{*}{ Occupation } & Worker & 59 & 10.3 \\
\hline & Civil servant & 57 & 9.9 \\
\hline & Peasant & 185 & 32.2 \\
\hline & Merchant & 33 & 5.7 \\
\hline & Medical staff & $4 I$ & 7.1 \\
\hline & Teacher & 27 & 4.7 \\
\hline & Other & 173 & 30.1 \\
\hline \multirow[t]{2}{*}{ Inhabitance } & Rural & 326 & 56.7 \\
\hline & Urban & 249 & 43.3 \\
\hline
\end{tabular}

was positively correlated with the HAMD score $(r=0.51$, $P<0.01)$. The SOC score had a negative correlation with the HAMD score $(r=-0.58, P<0.01)$.

\section{The Effect of SOC on the Relationship of Type C Personality and Depression Multiple Linear Regression Analysis}

With socio-demographic variables as the controlled variables, depression as the dependent variable, the dimensions of type $\mathrm{C}$ personality and SOC as predictive variables, a triple linear regression equation was established. The results are shown in Table 3. In Model I $\left(F=5.191, P<0.01, R^{2}=0.023\right)$, we found that the 


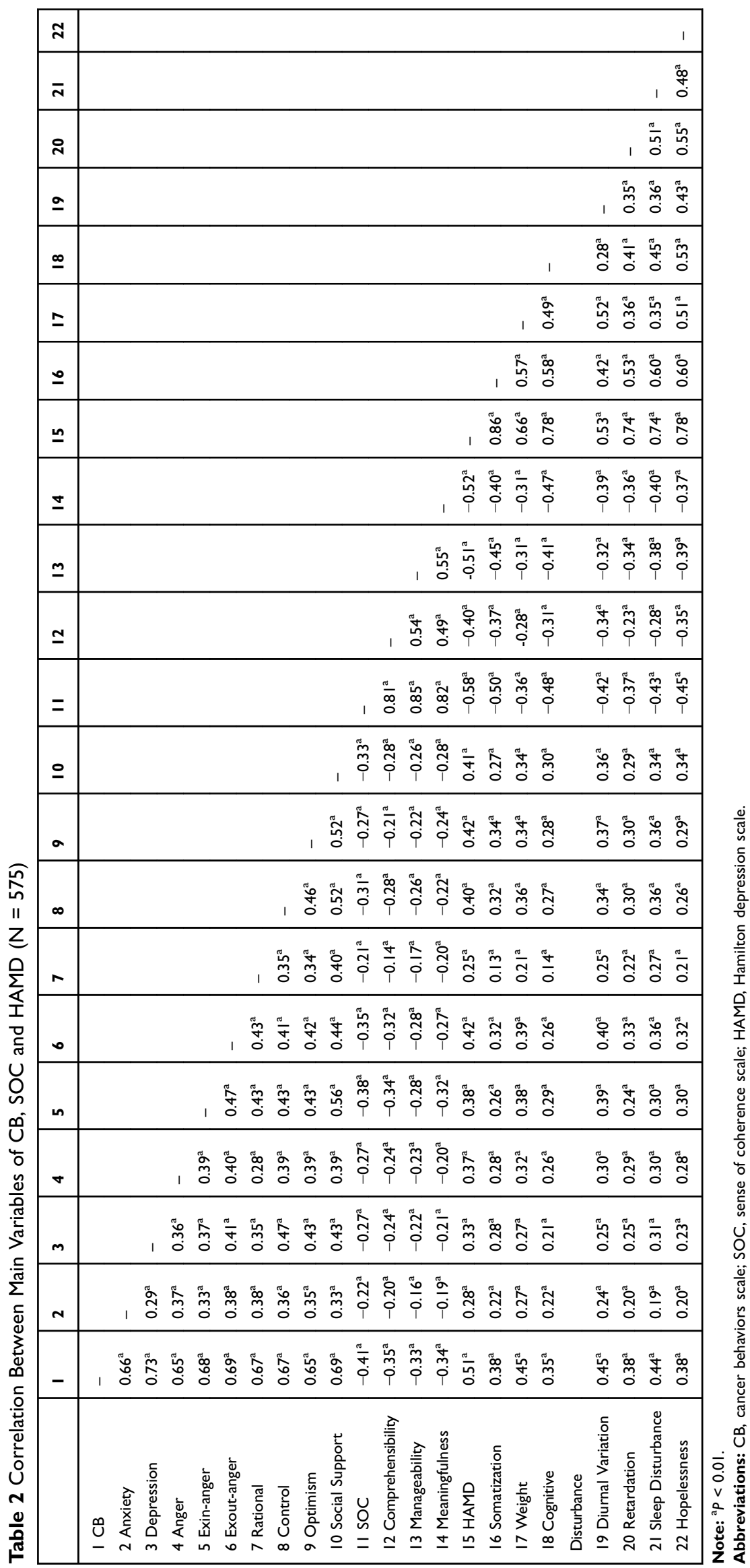


Table 3 Results of Multiple Linear Regression Analysis (Enter Method) ( $\mathrm{N}=575)$

\begin{tabular}{|c|c|c|c|c|c|c|c|}
\hline Models & Variables & $B(S E)$ & Beta & $t$ & $P$ & F value & Adjusted $R^{2}$ \\
\hline Model I & $\begin{array}{l}\text { Age } \\
\text { Spouse Status } \\
\text { Type of Surgery } \\
\text { Degree of Education } \\
\text { Monthly Income }\end{array}$ & $\begin{array}{l}0.042(0.021) \\
-1.695(0.58 I) \\
1.201(0.493) \\
-0.187(0.209) \\
-0.71 I(0.270)\end{array}$ & $\begin{array}{l}0.067 \\
-0.098 \\
0.082 \\
-0.030 \\
-0.088\end{array}$ & $\begin{array}{l}1.989 \\
-2.918 \\
2.437 \\
-0.897 \\
-2.638\end{array}$ & $\begin{array}{l}0.047 \\
0.004 \\
0.015 \\
0.370 \\
0.008\end{array}$ & $5.191^{\mathrm{a}}$ & 0.029 \\
\hline Model II & $\begin{array}{l}\text { Age } \\
\text { Spouse Status } \\
\text { Type of Surgery } \\
\text { Degree of Education } \\
\text { Monthly Income } \\
\text { Anxiety } \\
\text { Depression } \\
\text { Anger } \\
\text { Exin-anger } \\
\text { Exout-anger } \\
\text { Rational } \\
\text { Control } \\
\text { Optimism } \\
\text { Social Support }\end{array}$ & $\begin{array}{l}0.026(0.018) \\
-1.083(0.487) \\
0.953(0.414) \\
-0.217(0.174) \\
-0.264(0.227) \\
0.428(0.102) \\
0.252(0.116) \\
0.179(0.053) \\
0.172(0.086) \\
0.305(0.079) \\
0.104(0.053) \\
0.339(0.110) \\
0.020(0.036) \\
0.253(0.115)\end{array}$ & $\begin{array}{l}0.042 \\
-0.063 \\
0.065 \\
-0.035 \\
-0.033 \\
0.133 \\
0.082 \\
0.110 \\
0.076 \\
0.137 \\
0.071 \\
0.111 \\
0.036 \\
0.084\end{array}$ & $\begin{array}{l}I .47 \mid \\
-2.226 \\
2.303 \\
-1.245 \\
-1.161 \\
4.211 \\
2.170 \\
3.349 \\
2.002 \\
3.839 \\
1.951 \\
3.090 \\
0.554 \\
2.204\end{array}$ & $\begin{array}{l}0.142 \\
0.026 \\
0.022 \\
0.213 \\
0.246 \\
0.000 \\
0.030 \\
0.001 \\
0.046 \\
0.000 \\
0.051 \\
0.002 \\
0.580 \\
0.028\end{array}$ & $31.050^{\mathrm{b}}$ & 0.337 \\
\hline Model III & $\begin{array}{l}\text { Age } \\
\text { Spouse Status } \\
\text { Type of Surgery } \\
\text { Degree of Education Monthly } \\
\text { Income } \\
\text { Anxiety } \\
\text { Depression } \\
\text { Anger } \\
\text { Exin-anger } \\
\text { Exout-anger } \\
\text { Rational } \\
\text { Control } \\
\text { Optimism } \\
\text { Social Support } \\
\text { Comprehensibility } \\
\text { Manageability } \\
\text { Meaningfulness }\end{array}$ & $\begin{array}{l}0.012(0.016) \\
-0.483(0.431) \\
0.667(0.366) \\
-0.268(0.154) \\
0.073(0.202) \\
0.354(0.090) \\
0.247(0.103) \\
0.148(0.047) \\
0.070(0.076) \\
0.225(0.071) \\
0.045(0.047) \\
0.299(0.097) \\
0.009(0.032) \\
0.142(0.102) \\
-0.197(0.072) \\
-0.495(0.084) \\
-0.694(0.083)\end{array}$ & $\begin{array}{l}0.019 \\
-0.028 \\
0.046 \\
-0.044 \\
0.009 \\
0.110 \\
0.081 \\
0.091 \\
0.031 \\
0.101 \\
0.031 \\
0.098 \\
0.009 \\
0.047 \\
-0.075 \\
-0.192 \\
-0.254\end{array}$ & $\begin{array}{l}0.768 \\
-1.121 \\
1.822 \\
-1.743 \\
0.359 \\
3.921 \\
2.410 \\
3.130 \\
0.915 \\
3.188 \\
0.956 \\
3.079 \\
0.293 \\
1.396 \\
-2.727 \\
-5.897 \\
-8.368\end{array}$ & $\begin{array}{l}0.443 \\
0.263 \\
0.069 \\
0.082 \\
0.720 \\
0.000 \\
0.016 \\
0.002 \\
0.361 \\
0.001 \\
0.339 \\
0.002 \\
0.770 \\
0.163 \\
0.007 \\
0.000 \\
0.000\end{array}$ & $47.437^{b}$ & 0.486 \\
\hline
\end{tabular}

Notes: The variable of age was entered as a continuous variable. The other sociodemographic variables were entered as categorical variables. Spouse Status (0: no, I: have); Type of Surgery (I: Lumpectomy, 2: mastectomy); Degree of Education (I: elementary school or below, 2: junior high school, 3: high school, 4: undergraduate college, 5: postgraduate or above); Monthly Income (I: $<3,000,2: 3,000-5,000,3: 5,000-10,000,4: 10,000-20,000,5:>20,000)$. ${ }^{a} p<0.01$; ${ }^{b} p<0.001$.

socio-demographic variables account for $2.3 \%$ of the variation of depression, which accounted for a significant portion. Age, type of surgery, spouse status and monthly income were significant predictors in it. In Model II $\left(F=31.050, P<0.01, R^{2}=0.326\right)$, type C personality dimension was involved in the regression model after controlling for socio-demographic variables, all these variables explained $32.6 \%$ of the variation in depression, of which $30.3 \%$ were explained by type C personality. These variables of anger, exinanger, exout-anger, control and social support were recognized as significant predictors of depression in Model II, but age and monthly income became insignificant in it. In Model III $\left(F=47.437, P<0.01, R^{2}=\right.$ 0.475), SOC dimensions were included in the multiple linear regression model and additionally explained $14.9 \%$ variance of depression. Type of surgery and spouse status as predictors of depression were not 
significant anymore. The influence of various dimensions of type $\mathrm{C}$ personality on depression declined to some extent. For example, exin-anger and social support were no longer a significant predictor of depression. But three dimensions of SOC (ie, comprehensibility, comprehensibility manageability and meaningfulness) became significant. Moreover, there was no collinearity issue among the independent variables of the three models.

\section{Structural Equation Modeling}

The SEM was employed to verify the significance of the mediation model, and it consists of three latent variables (ie, $\mathrm{CB}, \mathrm{SOC}, \mathrm{HAMD}$ ) and 19 observed variables (dimensions of the three scales). Path analysis of the model is shown in Figure 2. It confirmed that type $\mathrm{C}$ personality was negatively correlated with SOC (path coefficient $=-0.524$ ) and positively correlated with depression (path coefficient $=0.323$ ). Meanwhile, SOC was negatively correlated with depression (path coefficient $=-0.514$ ). In Table 4 , the result of goodness-of-fit indices showed the SEM fitted with data well and was significant. The standardized indirect effect and total effect of type $\mathrm{C}$ personality on depression and the standardized direct effects between type C personality, SOC and depression are reported in Table 5. The bootstrapped 95\% confidence interval (CI) of indirect effect between $\mathrm{CB}$ and HAMD did not include $0(0.203-0.344)$, which indicated that SOC had a significant mediation effect on the relationship of type $\mathrm{C}$ personality and depression (path coefficient $=0.269$ ). It also demonstrated that $\mathrm{SOC}$ as a partial mediator, the effect on depression accounted for $45.2 \%(0.269 / 0.594)$ of the total effect. Hence, these above results indicated that the previous hypotheses (H1-H4) were all valid.

\section{Discussion}

Depression is one of the most common complications after the diagnosis of breast cancer, and it is further recognized as a significant determinant of quality of life. In this study, the overall prevalence of depression in breast cancer patients was $27.0 \%$, which is within the range of $8.1-89.2 \%$ reported in previous studies. ${ }^{38-40}$ An increasing number of studies reveal the importance of focusing on breast cancer patients' physical and mental health. However, the mediation effect of SOC on the relationship of type $\mathrm{C}$ personality and depression has rarely been reported in previous studies. Hence, the objective of this study has two parts: (i) analysing the relationship of type $\mathrm{C}$ personality, SOC and depression; (ii) investigating the potential mediation effect of SOC in the above-mentioned relationships.

\section{Correlation of Type C Personality, SOC and Depression}

The present study showed that type $\mathrm{C}$ personality had a positive relationship with depression. The more obvious type $\mathrm{C}$ personality carries, the more risk of depression, which was in accord with the findings of Conrad et al. ${ }^{41}$ People with type $\mathrm{C}$ personality are thought to over inhibit their real emotions and pursues perfection, especially in breast cancer patients. This lack of emotional release is thought to be associated with low self-confidence and selfefficacy in individuals, and enhance the generation of stress, thus further producing depressive symptoms. And specific intervention to reduce the depression in type $\mathrm{C}$ personality patients with breast cancer can be carried out in the future. ${ }^{13}$

We found that SOC was negatively correlated with type $\mathrm{C}$ personality. This finding was consistent with the points of Collins ${ }^{42}$ and Kase et al. ${ }^{43}$ To some extent, the type $\mathrm{C}$ personality has similarities with the personality characteristics of neuroticism. People with these characteristics are always pursuing perfection and forcing themselves to do things that are reluctant. However, SOC can be defined as a kind of positive psychology, and it emphasizes coping with psychological problems in a positive way. Thus, people with stronger psychological coherence are likely to have less characteristics of type $\mathrm{C}$ personality and can adopt a better way to express their emotions. Simultaneously, SOC was negatively correlated with depression as well, which was consistent with the findings of Kovi et al ${ }^{44}$ and Lopez-Martinez et al. ${ }^{18}$ A higher level of SOC can be flexibly adapted to specific circumstances, such as stress, depression, etc. In conclusion, the stronger SOC lowers the risk of depression.

\section{Mediation Effect}

Studies ${ }^{32-35}$ have shown that depression was significantly associated with many aspects, such as young women, single or divorced or widowed, mastectomy, low level of education and less incomes. In the present study, spouse status and monthly income were recognized as predictive factors of depression in Model I of the regression equation. However, in Model II and Model III, type of surgery, income and spouse status were no longer significant. This revealed that such variables may act on the depression of newly diagnosed 


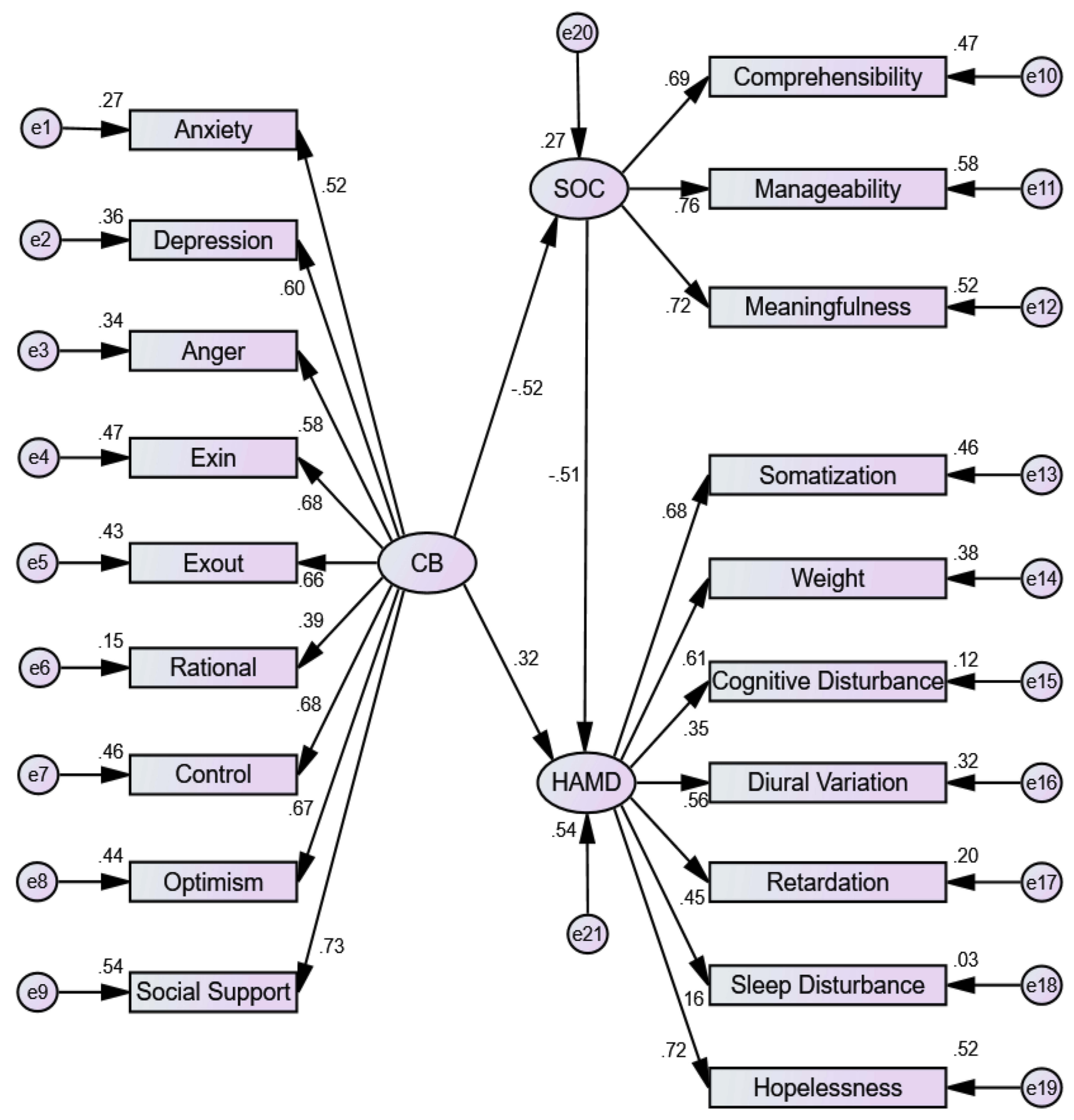

Figure 2 Pathway coefficients of the SEM $(\mathrm{N}=575)$.

Abbreviations: CB, cancer behaviors scale; SOC, sense of coherence scale; HAMD, Hamilton depression scale; el-el9, measurement errors of observed variables; e20-e2I, residuals that may affect the latent variables.

breast cancer patients by type C personality or SOC. The results of multiple linear regression analysis indicated that type $\mathrm{C}$ personality exerted an indirect effect on depression through SOC. According to the comparison of Model I, Model II, and Model III, it was revealed that $30.3 \%$ of variance was explained by type C personality and $14.9 \%$ was explained by SOC. Moreover, the results of SEM confirmed that SOC played a partial mediating role between type $\mathrm{C}$ personality and depression. It also indicated that in addition to sense of coherence, there are other mediating variables between type $\mathrm{C}$ personality and depression, which deserve further exploration and verification. Thus, it was confirmed by this present research that type $\mathrm{C}$ personality not only directly affects the depression but also indirectly 
Table 4 The Goodness-of-Fit Indices of the SEM ( $N=575)$

\begin{tabular}{|l|l|l|l|l|l|l|l|}
\hline Index & $\chi^{2}$ IDf & GFI & AGFI & RMSEA & NFI & CFI \\
\hline Statistical value & 2.970 & 0.951 & 0.938 & 0.047 & 0.911 & 0.939 & 0.939 \\
\hline
\end{tabular}

Notes: An SEM was considered to have a good fit if all path coefficients were significant at the level of $0.05 ; \chi^{2} / \mathrm{df}$, was $<3$; the root-mean-square error of approximation (RMSEA) was <0.08; as well as the goodness-of-fit index (GFI), the adjusted goodness-of-fit index (AGFI); the normed fit index (NFI), the comparative fit index (CFI) and the incremental fit index (IFI) were $\geq 0.90$.

Table 5 The Standardized Total, Indirect, and Direct Effects Among Type C Personality, SOC and Depression ( $\mathrm{N}=575)$

\begin{tabular}{|c|c|c|c|c|c|c|c|c|}
\hline \multirow{3}{*}{\multicolumn{2}{|c|}{ Model Pathway }} & \multirow{4}{*}{$\begin{array}{l}\text { Point Estimate } \\
0.594\end{array}$} & \multirow{2}{*}{\multicolumn{2}{|c|}{ Product of Coefficients }} & \multicolumn{4}{|c|}{ Bootstrap $^{a}$} \\
\hline & & & & & \multicolumn{2}{|c|}{ Bias-Corrected $95 \% \mathrm{Cl}$} & \multicolumn{2}{|c|}{ Percentile $95 \% \mathrm{Cl}$} \\
\hline & & & \multirow{2}{*}{$\frac{S E}{0.037}$} & \multirow{2}{*}{$\frac{Z}{16.054}$} & \multirow{2}{*}{$\frac{\text { Lower }}{0.516}$} & \multirow{2}{*}{$\begin{array}{l}\text { Upper } \\
0.662\end{array}$} & \multirow{2}{*}{$\frac{\text { Lower }}{0.516}$} & \multirow{2}{*}{$\frac{\text { Upper }}{0.662}$} \\
\hline Total effect & $\mathrm{CB} \rightarrow \mathrm{HAMD}$ & & & & & & & \\
\hline Indirect effect & $\mathrm{CB} \rightarrow \mathrm{HAMD}$ & 0.269 & 0.036 & 7.472 & 0.203 & 0.344 & 0.201 & $0.34 I$ \\
\hline Direct effect & $\begin{array}{l}\mathrm{CB} \rightarrow \mathrm{HAMD} \\
\mathrm{CB} \rightarrow \mathrm{SOC} \\
\mathrm{SOC} \rightarrow \mathrm{HAMD}\end{array}$ & $\begin{array}{l}0.323 \\
-0.524 \\
-0.514\end{array}$ & $\begin{array}{l}0.044 \\
0.039 \\
0.054\end{array}$ & $\begin{array}{l}7.341 \\
-13.435 \\
-9.518\end{array}$ & $\begin{array}{l}0.236 \\
-0.593 \\
-0617\end{array}$ & $\begin{array}{l}0.410 \\
-0.443 \\
-0.405\end{array}$ & $\begin{array}{l}0.235 \\
-0.594 \\
-0.617\end{array}$ & $\begin{array}{l}0.409 \\
-0.443 \\
-0.405\end{array}$ \\
\hline
\end{tabular}

Note: ${ }^{a}$ Number of bootstrap samples: 2000.

Abbreviations: $\mathrm{CB}$, cancer behaviors scale; SOC, sense of coherence scale; HAMD, Hamilton depression scale.

explains the depression through SOC. It also revealed that the one who has high levels of SOC would be less likely to suffer from depression.

With regard to our findings, we can explain the mediating role of SOC with the following points. SOC is a health promotion factor that can flexibly adopt appropriate strategies to accommodate emotional changes. When an individual experience negative emotions, the SOC will play a protective buffer role to make them have a better control and guide their emotions, stop over-suppressing their true feelings, make people more confident, and reduce the incidence of depression. At first, Antonovsky ${ }^{30}$ argued that $\mathrm{SOC}$ is a relatively stable sense of confidence, but it is thought to change with external or internal factors in a particular circumstance. SOC is considered to be more dynamic and flexible than before. It can change over time or be improved by some interventions. ${ }^{45,46}$ Therefore, some effective interventions should be developed to improve the SOC in order to counter the bad emotions. Such an intervention should be designed around the central tenets of SOC (ie, comprehensibility, manageability, meaningfulness) to be delivered to the newly diagnosed breast cancer patient with the following: (1) From an internal perspective, guide the patients to face up to negative emotions; from an external perspective, help them to understand the pathogenesis, treatment options and prognosis conditions of breast cancer. (2) Teach and encourage patients to mobilize all available resources and take active measures to address the challenges posed by cancer. (3) Help them to develop strategies to manage emotions and cope with breast cancer in an adaptive manner is valuable and meaningful for a healthy life.

Limitations of the present study: (1) The data collection from only one public hospital in Zhengzhou, Henan Province, China, and the convenient sampling method limit the generalizability of our findings. (2) In this study, we only discussed the mediating role of SOC in the relationship between type $\mathrm{C}$ personality and depression. However, the mediation effect of SOC is partial, there may be some other variables existed in the SEM, which has not been confirmed, such as self-efficacy, hope and spirituality. (3) At the time of data collection, therapeutic schedule for some patients has not been determined. Therefore, the influence of treatment on depression was not clear in this study, which should be completed in the future. (4) The participants of this study were only newly diagnosed breast cancer patients within 1 week after diagnosis, considering that their psychological processes would change over time. A cross-sectional research cannot accurately explain the mediation effect of SOC in different periods. Therefore, a longitudinal survey can be conducted in future to explore the changing trend of the mediating role of SOC.

\section{Conclusion}

The present study explored the mediation effect of SOC in the relationship of type $\mathrm{C}$ personality and depression. Newly diagnosed breast cancer patients are more likely to 
use positive strategies to counter type $\mathrm{C}$ personality when they experience high levels of SOC, thereby reducing the incidence of depression. Therefore, the findings have implications for nurses and healthcare personnel. Early and targeted psychological interventions on SOC for newly diagnosed breast cancer patients are needed to alleviate the symptom of depression. By acknowledging the three aspects of SOC, healthcare providers can provide relevant, targeted information and health education and psychological guidance to cancer patients to reduce their depression. In addition, further studies will investigate the influence of the type of surgery and treatment in the mediation model with longitudinal designs, and explore other potential mediators between type $\mathrm{C}$ personality and depression.

\section{Abbreviations}

SOC, sense of coherence; $\mathrm{CB}$, cancer behavior scale; HAMD, Hamilton depression scale; SEM, structural equation modeling.

\section{Acknowledgements}

We would like to thank Professor Martyn Jones and all participants.

\section{Author Contributions}

All authors contributed to data analysis, drafting or revising the article, gave final approval of the version to be published, and agree to be accountable for all aspects of the work.

\section{Funding}

This research is funded by the Medical Science and Technology Project of Henan Province (Grant No. SBGJ201 8003) and the Doctoral Candidate Innovation Project of Zhengzhou University (2018).

\section{Disclosure}

The authors have no conflicts of interest to disclose.

\section{References}

1. Bray F, Ferlay J, Soerjomataram I, et al. Global cancer statistics 2018: GLOBOCAN estimates of incidence and mortality worldwide for 36 cancers in 185 countries. CA Cancer J Clin. 2018;68(6):394-424. doi: $10.3322 /$ caac.v68.6

2. Li T, Mello-Thoms C, Brennan PC. Descriptive epidemiology of breast cancer in China: incidence, mortality, survival and prevalence. Breast Cancer Res Treat. 2016;159(3):395-406. doi:10.1007/s10549016-3947-0
3. Fan L, Strasser-Weippl K, Li JJ, et al. Breast cancer in China. Lancet Oncol. 2014;15(7):e279-e289. doi:10.1016/S1470-2045(13)70567-9

4. Montagna G, Schneeberger AR, Rossi L, et al. The impact of depression on adherence to organized and opportunistic breast cancer screening. Eur J Cancer Prev. 2019;44:S44-S45.

5. Kaminska M, Kubiatowski T, Ciszewski T, et al. Evaluation of symptoms of anxiety and depression in women with breast cancer after breast amputation or conservation treated with adjuvant chemotherapy. Ann Agric Environ Med. 2015;22(1):185-189. doi: $10.5604 / 12321966.1141392$

6. Maass SW, Roorda C, Berendsen AJ, Verhaak PF, de Bock GH. The prevalence of long-term symptoms of depression and anxiety after breast cancer treatment: a systematic review. Maturitas. 2015;82(1):100-108.

7. Stafford L, Judd F, Gibson P, et al. Anxiety and depression symptoms in the 2 years following diagnosis of breast or gynaecologic cancer: prevalence, course and determinants of outcome. Support Care Cancer. 2015;23(8):2215-2224. doi:10.1007/s00520-014-2571-y

8. Howard-Anderson J, Ganz PA, Bower JE, Stanton AL. Quality of life, fertility concerns, and behavioral health outcomes in younger breast cancer survivors: a systematic review. $J$ Natl Cancer Inst. 2012;104(5):386-405. doi:10.1093/jnci/djr541

9. Özlem B, Ece T, Tuğba Y. Does perceived social support buffer the negative effects of type $\mathrm{C}$ personality on quality of life of breast cancer patients? Soc Indic Res. 2014;119:791-801. doi:10.1007/ s11205-013-0503-8

10. Cardenal V, Ortiz-Tallo M, Martin FI, Martinez LJ. Life stressors, emotional avoidance and breast cancer. Span J Psychol. 2008;11 (2):522-530. doi:10.1017/S1138741600004522

11. Baltrusch HJ, Stangel W, Waltz ME. Cancer from the biobehavioral perspective: the type C pattern. Act Nerv Super (Praha). 1988;30 (1): $18-21$.

12. Qu GF, Wang C. Research of correlation between type C personality and malignant tumor. J Mod Oncol. 2018;26(09):1458-1462.

13. Guo LN, Liu YJ, Wang J, et al. Research progress of the correlation between C-type personality and malignant tumor. Mod Preventive Med. 2019;46(08):1524-1527.

14. Antonovsky A. Unraveling the Mystery of Health. How People Manage Stress and Stay Well. Jossey-bass; 1987:26-38.

15. Geyer S. Some conceptual considerations on the sense of coherence. Soc Sci Med. 1997;44(12):1771-1779. doi:10.1016/S0277-9536(96) 00286-9

16. Drageset J, Espehaug B, Kirkevold M. The impact of depression and sense of coherence on emotional and social loneliness among nursing home residents without cognitive impairment - a questionnaire survey. J Clin Nurs. 2012;21(7-8):965-974. doi:10.1111/j.1365-2702.2011.03932.x

17. Keil DC, Vaske I, Kenn K, Rief W, Stenzel NM. With the strength to carry on: the role of sense of coherence and resilience for anxiety, depression and disability in chronic obstructive pulmonary disease. Chron Resp Dis. 2017;14(1):11-21. doi:10.1177/1479972316654286

18. Lopez-Martinez C, Frias-Osuna A, Del-Pino-Casado R. Sense of coherence and subjective overload, anxiety and depression in caregivers of elderly relatives. Gac Sanit. 2019;33(2):185-190. doi:10.1016/j.gaceta.2017.09.005

19. Koyama A, Matsushita M, Ushijima H, Jono T, Ikeda M. Association between depression, examination-related stressors, and sense of coherence: the Ronin-Sei study. Psychiatry Clin Neurosci. 2014;68 (6):441-447. doi:10.1111/pcn.2014.68.issue-6

20. Rohani C, Abedi HA, Omranipour R, Langius-Eklof A. Healthrelated quality of life and the predictive role of sense of coherence, spirituality and religious coping in a sample of Iranian women with breast cancer: a prospective study with comparative design. Health Qual Life Outcomes. 2015;13:40. doi:10.1186/s12955-015-0229-1

21. Lindblad C, Langius-Eklof A, Petersson LM, et al. Sense of coherence is a predictor of survival: a prospective study in women treated for breast cancer. Psychooncology. 2018;27 (6):1615-1621. doi:10.1002/pon.v27.6 
22. Guo LN, Liu YJ, McCallum J, et al. Perceived stress and depression amongst older stroke patients: sense of coherence as a mediator? Arch Gerontol Geriatr. 2018;79:164-170. doi:10.1016/j.archger.2018.08.010

23. Baron RM, Kenny DA. The moderator-mediator variable distinction in social psychological research: conceptual, strategic, and statistical considerations. J Pers Soc Psychol. 1986;51(6):1173-1182. doi:10.1037/0022-3514.51.6.1173

24. MacKinnon DP, Luecken LJ. How and for whom? Mediation and moderation in health psychology. Health Psychol. 2008;27(2S):S99 S100. doi:10.1037/0278-6133.27.2(Suppl.).S99

25. MacKinnon DP, Luecken LJ. Statistical analysis for identifying mediating variables in public health dentistry interventions. J Public Health Dent. 2011;71(Suppl 1):S37-S46. doi:10.1111/j.17527325.2011.00252.x

26. MacKinnon DP, Pirlott AG. Statistical approaches for enhancing causal interpretation of the $\mathrm{M}$ to $\mathrm{Y}$ relation in mediation analysis. Pers Soc Psychol Rev. 2015;19(1):30-43. doi:10.1177/1088868314542878

27. Chinese Anti-Cancer Association COBC. Guidelines and standards for diagnosis and treatment of breast cancer by Chinese anti-cancer association (2019). China Oncol. 2019;29(8):609-680.

28. Thompson B. Ten Commandments of Structural Equation Modeling. American Psychological Association; 2000.

29. Zhang ZJ. Manual of behavioral medicine scale. Chin J Behav Med Sci. 2001;10(10):19-24.

30. Antonovsky A. Unraveling the mystery of health: how people manage stress and stay well. J Nerv Mental Dis. 1987;177(7):439-440.

31. Hamilton M. A rating scale for depression. J Neurol Neurosurg Psychiatry. 1960;23(1):56-62. doi:10.1136/jnnp.23.1.56

32. Chen X, Zheng Y, Zheng W, et al. Prevalence of depression and its related factors among Chinese women with breast cancer. Acta Oncol. 2009;48(8):1128-1136. doi:10.3109/02841860903188650

33. Boing L, Pereira GS, Araujo C, et al. Factors associated with depression symptoms in women after breast cancer. Rev Saude Publica. 2019;53:30. doi:10.11606/S1518-8787.2019053000786

34. Hopwood P, Sumo G, Mills J, Haviland J, Bliss JM. The course of anxiety and depression over 5 years of follow-up and risk factors in women with early breast cancer: results from the UK Standardisation of Radiotherapy Trials (START). Breast. 2010;19(2):84-91. doi:10.1016/j.breast.2009.11.007

35. Schlegel RJ, Manning MA, Molix LA, Talley AE, Bettencourt BA. Predictors of depressive symptoms among breast cancer patients during the first year post diagnosis. Psychol Health. 2012;27 (3):277-293. doi:10.1080/08870446.2011.559232
36. MacKinnon DP, Lockwood CM, Hoffman JM, West SG, Sheets V. A comparison of methods to test mediation and other intervening variable effects. Psychol Methods. 2002;7(1):83-104. doi:10.1037/1082989X.7.1.83

37. Sobel ME. Asymptotic confidence intervals for indirect effects in structural equation models. Sociol Methodol. 1982;13(13):290-312. doi: $10.2307 / 270723$

38. Pilevarzadeh M, Amirshahi M, Afsargharehbagh R, et al. Global prevalence of depression among breast cancer patients: a systematic review and meta-analysis. Breast Cancer Res Treat. 2019;176:519533. doi:10.1007/s10549-019-05271-3

39. Yang YL, Liu L, Wang Y, et al. The prevalence of depression and anxiety among Chinese adults with cancer: a systematic review and meta-analysis. BMC Cancer. 2013;13:393. doi:10.1186/1471-2407-13-393

40. Jacob L, Kalder M, Kostev K. Incidence of depression and anxiety among women newly diagnosed with breast or genital organ cancer in Germany. Psychooncology. 2017;26(10):1535-1540. doi:10.1002/pon.v26.10

41. Conrad R, Wegener I, Imbierowicz K, Liedtke R, Geiser F. Alexithymia, temperament and character as predictors of psychopathology in patients with major depression. Psychiatry Res. 2009;165(1-2):137-144. doi:10.1016/j.psychres.2007.10.013

42. Collins A. Postpartum depressive symptoms of husbands and wives as related to their sense of coherence, personality traits and quality of dyadic relationship. J Psychosom Res. 2019;121:. doi:10.1016/j. jpsychores.2019.03.022

43. Kase T, Ueno Y, Oishi K. The overlap of sense of coherence and the Big Five personality traits: a confirmatory study. Health Psychol Open. 2018;5 (2):2055102918810654. doi:10.1177/2055102918810654

44. Kovi Z, Odler V, Gacsalyi S, et al. Sense of coherence as a mediator between personality and depression. Pers Indiv Differ. 2017;114:119124. doi:10.1016/j.paid.2017.03.064

45. Sagy S, Antonovsky H. The development of the sense of coherence: a retrospective study of early life experiences in the family. Int J Aging Hum Dev. 2000;51(2):155-166. doi:10.2190/765L-K6NV-JK52-UFKT

46. Vastamaki J, Moser K, Paul KI. How stable is sense of coherence? Changes following an intervention for unemployed individuals. Scand $J$ Psychol. 2009;50(2):161-171. doi:10.1111/sjop.2009.50.issue-2
Neuropsychiatric Disease and Treatment

\section{Publish your work in this journal}

Neuropsychiatric Disease and Treatment is an international, peerreviewed journal of clinical therapeutics and pharmacology focusing on concise rapid reporting of clinical or pre-clinical studies on a range of neuropsychiatric and neurological disorders. This journal is indexed on PubMed Central, the 'PsycINFO' database and CAS, and is the official journal of The International Neuropsychiatric Association (INA). The manuscript management system is completely online and includes a very quick and fair peer-review system, which is all easy to use. Visit http://www.dovepress.com/testimonials.php to read real quotes from published authors. 